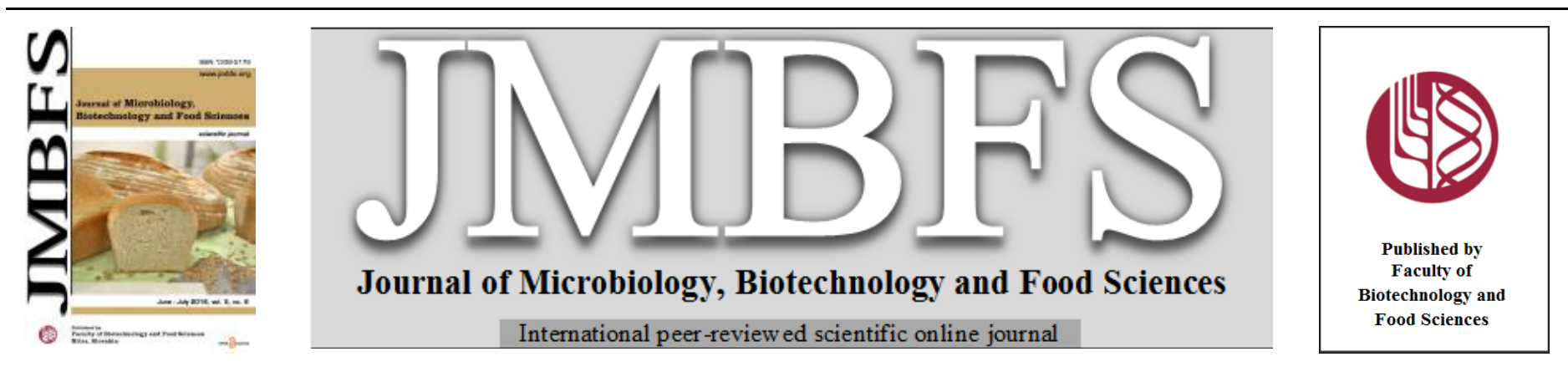

\title{
INCIDENCE OF FILAMENTOUS FUNGI WITH TOXIGENIC POTENTIAL ON SAMPLES OF FEED AND RAW MATERIALS FOR THEIR MANUFACTURE
}

\author{
Rodrigo Vera ${ }^{*}$, Leonardo Arosemena, María Ángeles Calvo-Torras
}

Address(es): Mr. Rodrigo Vera,

University Autonomous of Barcelona, Faculty of Veterinary, Animal Health and Anatomy Department, Edifici V Campus UAB, 08193 Bellaterra, Spain, +34935811298 .

*Corresponding author: Rodrigo.Vera@uab.cat

doi: $10.15414 / j m b f s .2016 .5 .6 .599-601$

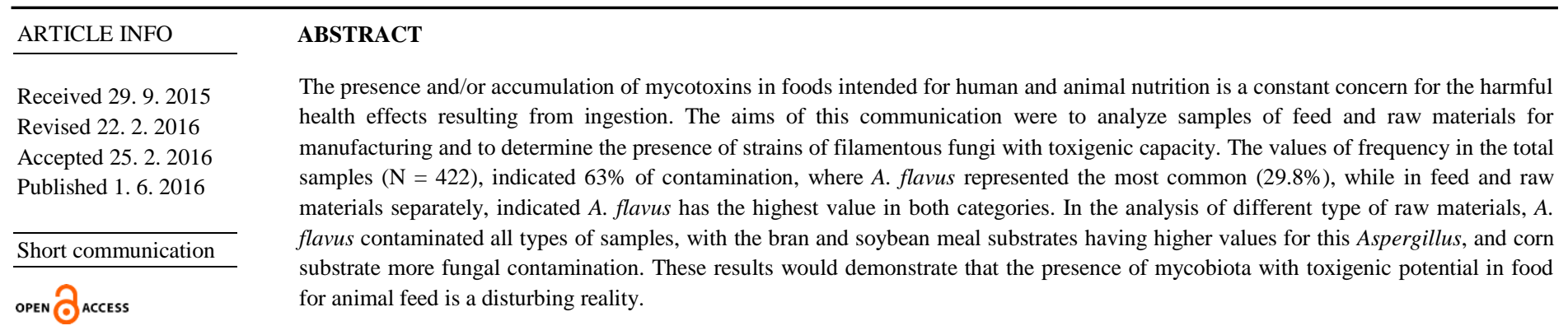

Keywords: Aspergillus flavus, feed, filamentous fungi

\section{INTRODUCTION}

For the reason that many food intended for animal nutrition are an important channel introducing hazards on the human food chain, it is safety should be evaluated and valued before being fed to the animals. These following assessment processes reviewed various aspects of the presence of some species of microorganism, implying contemplate the safety of the animals as well as humans who can consume remains of them or their metabolites that can stay in food of animal origin (FAO/WHO, 2007).

Many species of filamentous fungi are able to produce mycotoxins, but those belonging to the genera Aspergillus, Fusarium and Penicillium are especially important in notorious analysis of the contamination of food for human and animal consumption, as there can be consequent adverse effects to health if they are ingested (Bryden, 2011), estimating that at least 300 of these metabolites are potentially toxic to animals and humans (Huwig et al, 2001).

Mycotoxins are defined as "secondary metabolites produced and accumulated by certain species of fungi, whose ingestion, inhalation or skin absorption reduces performance, sickness or kills animals or people" (Pitt, 1996; Aissaoui et al.,1999) thereby denominating mycotoxicosis to toxic response caused by the mycotoxin in humans and animals (Osborne, 1982; Jand et al., 2005).

While mycotoxin production from fungi depends on environmental conditions and food storage, determining the degree of contamination of feed and raw materials, potentially indicates the presence of these metabolites in these substrates thus allowing us to monitor and control measures throughout the production chain. For this reason the objective of our study was to assess the degree of contamination in feed and raw materials used for manufacturing by identifying mycelial fungi with mycotoxigenic potential.

\section{MATERIAL AND METHODS}

\section{Samples}

We analyzed 422 samples, 236 of which were feed samples and 186 were raw materials (10 different substrates) from different companies located in the Iberian Peninsula dedicated to the animal sector.

\section{Isolation and identification of filamentous fungi}

The presence of certain species and genera of filamentous fungi with potential toxigenicity were isolated and determined. This included isolating: Aspergillus flavus, Aspergillus niger and Fusarium spp.

To isolate this mycobiota in feed and raw materials, the samples were suspended in 1/10 concentration of sterile Ringer's solution eukaryote. The bottle was shaken vigorously for 20 seconds in order to release fungal propagules adhered to the surface, and $0.1 \mathrm{~mL}$ of the sample was inoculated on Sabouraud Dextrose Agar plates with chloramphenicol (LIOFILCHEM $®$ ), and then incubated in a conventional oven at $28^{\circ} \mathrm{C}$ for 4-7 days.

\section{Identification of fungi}

After the incubation, the plates with positive growth of fungi were analysed and identified macroscopically and microscopically. Phenotypes such as colour were analysed macroscopically, such as colour of mycelium, hyphae and conidia. Whereas reproductive structures, form of conidiophores and conidia were analysed microscopically. The species Aspergillus were identified according to the information provided by Raper \& Fennell (1965) and Koneman et al., (1999), and Nelson et al., (1983) for the genus Fusarium.

\section{Data analysis}

The isolation frequency (Fr) and relative density (RD) of species were calculated according to Gonzalez et al., (1995) as follows:

Fr (\%): (number of samples whit a species or genus / Total number of samples) X 100

$\mathrm{RD}(\%)$ : (number of isolates of a species or genus / Total number of fungi isolated) $\mathrm{X} 100$

\section{RESULTS AND DISCUSSION}

The results obtained in our study indicate the present mycobiota and were consistent with the findings by some authors as Richard et al., (2007), Jeswal (1990) and Phillips et al., (1996) where in samples collected from in food industries that the presence of A. flavus, A. niger and Fusarium spp. was detected. 


\section{Contamination of potential toxigenic fungi in samples}

The presence of filamentous fungi in products for human and animal nutrition and has been investigated by various authors for decades, with the objective being to take controlled measures and implement recommendations of good agricultural and manufacturing practices (González-Pereyra et al. , 2008). Our results of the presence of filamentous fungi in the total sample (feed and raw materials) indicate that $63.03 \%$ are contaminated with at least one possible strain having toxigenic capacity. Of the total feed analysed, $61.4 \%$ of contamination existed, whereas in the raw samples, there was $65.05 \%$ associated to the development of mycobiota (Table 1).

Table 1 Isolation Frecueny of samples contamined (\%) whit toxigenic potential filamentous fungi analyzed in this study.

\begin{tabular}{lccc}
\hline & $\mathbf{n}$ & $\mathbf{n}+$ & $\mathbf{F r}(\boldsymbol{\%})$ \\
\hline Total samples & 422 & 266 & 63.03 \\
Feed & 236 & 145 & 61.44 \\
Raw material & 186 & 121 & 65.05
\end{tabular}

Legends: $\mathrm{n}$ - number of samples, $\mathrm{n}+$ - number of contaminated samples with a filamentous fungus analyzed in this study

\section{Identification of filamentous fungi and total contamination of feed}

The frequency values in the filamentous fungi identification found in the tota samples (Fig. 1), indicated that Aspergillus flavus is the specie whit a higher contamination value $(29.8 \%)$, followed by the Fusarium genera $(20.8 \%)$ and Aspergillus niger specie (9.7\%). The remaining 39.8\% showed no presence by any of these toxigenic strains.

This results are in accordance whit the findings of others authors who have collected samples in food industries where exists the presence of these filamentous fungi exist (Richard et al., 2007; Jeswal, 1990; Philips et al., 1996). It is interesting that the percentage didn't present contamination for species/genera of toxigenic fungi $(39.8 \%)$, in contrast to other similar studies where total feed samples showed an association to mycobiota (Glenn, 2007), this would indicate the presence of necessary contamination control measures in food companies, such as application of post-harvest antifungal treatments, control temperature and relative humidity in storage.

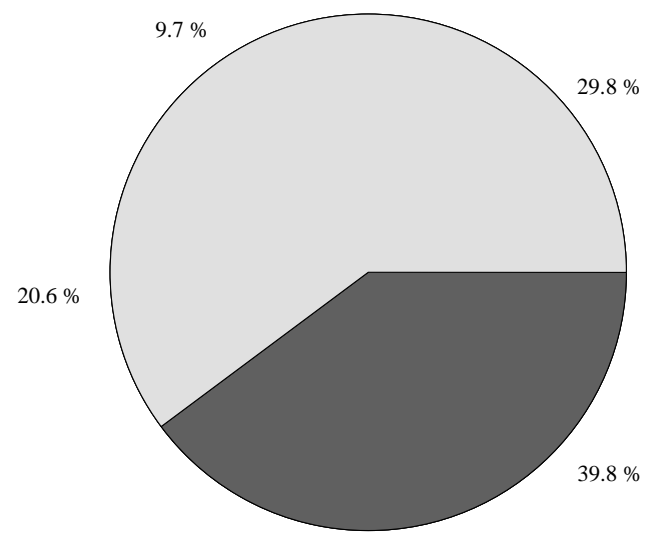

Figure 1 Distribution of potentially toxigenic filamentous fungi in all samples analyzed

\section{Relative density of filamentous fungi whit toxigenic potential in total samples}

The results indicated that A. flavus has the highest value of relative density in both feed and raw material, followed by Fusarium spp. and A. niger (Table 2). These results are similar to other authors, in relation to the species or genera of filamentous fungi found, however there are differences in the values of relative density, for example González Pereyra et al., (2008) found $13.9 \%$ for A. flavus, $8.33 \%$ in A. niger, and $100 \%$ for Fusarium spp. Meanwhile Rosa et al., (2009) found that Fusarium spp. contaminates all samples, A. flavus $50.0 \%$, and A. niger $20 \%$. The difference in values could be related to several factors such as: the origin of the samples, time of collection, storage and environmental characteristics and variables that favor the development of filamentous fungi.
Table 2 Relative density of species / genera of filamentous fungi on total samples analyzed in this study.

\begin{tabular}{lcc}
\hline $\mathbf{H F}$ & Feed $(\mathbf{n}=\mathbf{2 3 6})$ & Raw material $(\mathbf{n = 1 8 6})$ \\
\hline Aspergillus flavus & 28.38 & 24.15 \\
\hline Aspergillus niger & 8.89 & 11.82 \\
\hline Fusarium spp. & 24.15 & 18.27 \\
\hline
\end{tabular}

Legends: HF - specie / genera of filamentous fungi analyzed in this study

In the raw materials (Table 3), the results indicated that each type of substrate is contaminated by one or more toxigenic fungi, where corn, soybean meal, and bran have the highest frequency of contamination $(>80.0 \%)$. These results agree with those obtained by authors in studies on corn when used as a raw material feed (Mngadi et al., 2008; Pereyra et al., 2010) which indicates that this is the substrate with the highest levels of contamination, a high degree of deterioration, and in some cases accumulation and mycotoxins. Also the results obtained by Lanier et al., (2009) in rapeseed, are similar to species / genera of filamentous fungi determined in our study.

Table 3 Frequency and relative density of species / genera of filamentous fungi evaluated in this study on substrates used as raw materials in feed production`s.

\begin{tabular}{|c|c|c|c|c|c|}
\hline \multirow[b]{2}{*}{ Raw materials } & \multirow[b]{2}{*}{$\mathbf{n}$} & \multirow[b]{2}{*}{$\operatorname{Fr}(\%)$} & \multicolumn{3}{|c|}{ RD (\%) } \\
\hline & & & A. flavus & A. niger & $\begin{array}{c}\text { Fusarium } \\
\text { spp. }\end{array}$ \\
\hline Barley & 19 & 42.1 & 26.32 & - & 15.79 \\
\hline Rapeseed & 7 & 42.9 & 28.57 & 14.29 & - \\
\hline Carob & 8 & 50.0 & 25.0 & 25.0 & - \\
\hline Sunflower & 8 & 62.5 & 37.50 & 12.50 & 12.50 \\
\hline Soybean meal & 5 & 80.0 & 60.00 & - & 20.00 \\
\hline Corn & 30 & 90.0 & 33.33 & 20.00 & 36.37 \\
\hline Bran & 6 & 83.3 & 66.67 & 16.67 & - \\
\hline Soy & 19 & 68.4 & 42.11 & 15.79 & 10.53 \\
\hline Wheat & 29 & 72.4 & 31.03 & 10.34 & 31.03 \\
\hline Other ingredients & 55 & 56.4 & 34.55 & 9.09 & 12.73 \\
\hline
\end{tabular}

\section{CONCLUSION}

The results demonstrate that the presence of mycobiota with toxigenic potential in food for animal feed is a disturbing reality and by eating the positive samples the probability and occurrence and / or accumulation of mycotoxins aflatoxins, ochratoxin, fumonisin and zearalelona type can cause a significant risk to animal and human health.

It should be emphasized that although the presence of these filamentous fungi does not necessarily indicate the presence of mycotoxin, there still is a possibility that some of the samples who did not present contamination may have accumulated mycotoxins along the productive chain (Pitt, 1996), therefore the consumption of the samples whit no sign of presence of mycobiota could still present a risk to the health of the animal.

Finally, while it is important to detect potential toxigenic species in foods such as assessing of the potential risks to animal or human health by the presence of these, it is also necessary to supplement this study with quantitative detection of mycotoxins, as currently legislation regulates the presence of these metabolites and not the presence and / or concentration of filamentous fungi in products intended for human and animal consumption.

Acknowledgments: The Group of Research in Applicated Microbiology and Enviromental of University Autonomous of Barcelona.

\section{REFERENCES}

AISSAOUI, H., CALVO TORRAS, M. A., \& AGUT BONSFILLS, M. (1999) Las micotoxinas en los alimentos. El Farmacéutico, (233), 88-99.

BRYDEN, W. L. (2011). Mycotoxins: Natural food chain contaminants and human health. http://dx.doi.org/10.1016/B978-0-444-52272-6.00701-7

FAO/WHO. (2007). Animal feed impact on food safety; Report of the FAO/WHO Expert Meeting, FAO Headquarters, Rome, 8-12 October 2007.

GLENN, A. E. (2007). Mycotoxigenic Fusarium species in animal feed. Anima Feed Science and Technology, 137(3), 213-240. http://dx.doi.org/10.1016/j.anifeedsci.2007.06.003

GONZÁLEZ, H. H. L., RESNIK, S. L., BOCA, R. T., \& MARASAS, W. F. O.

(1995). Mycoflora of Argentinian corn harvested in the main production area in 1990. Mycopathologia, 130(1), 29-36. http://dx.doi.org/10.1007/BF01104346 
GONZÁLEZ PEREYRA, M. L., PEREYRA, C. M., RAMIREZ, M. L., ROSA, C. D. R., DALCERO, A. M., \& CAVAGLIERI, L. R. (2008). Determination of mycobiota and mycotoxins in pig feed in central Argentina. Letters in applied microbiology, 46(5), 555-561. http://dx.doi.org/10.1111/j.1472765X.2008.02347.X

HUWIG, A., FREIMUND, S., KÄPPELI, O., \& DUTLER, H. (2001). Mycotoxin detoxication of animal feed by different adsorbents. Toxicology letters, 122(2), 179-188. http://dx.doi.org/10.1016/S0378-4274(01)00360-5

JAND, S. K., KAUR, P., \& SHARMA, N. S. (2005). Mycoses and mycotoxicosis in poultry: A review. The Indian Journal of Animal Sciences, 75(4).

JESWAL, P. (1990). Mycotoxin contamination in cattle feeds from Bihar. National Academy Science Letters, 13(12), 431-433.

KONEMAN E, ALLEN S, JANDA W, SCHRECKENBERGER P, WINN W (Ed.). Diagnóstico Microbiológico (5th ed.). Argentina, Editorial Médica Panamericana., 1999.

MNGADI, P. T., GOVINDEN, R., \& ODHAV, B. (2008). Co-occurring mycotoxins in animal feeds. African Journal of Biotechnology, 7(13)

Nelson, P. E., Toussoun, T. A., \& Marasas, W. F. O. (1983). Fusarium species: an illustrated manual for identification. http://dx.doi.org/10.2307/3793311

OSBORNE, B. G. (1982). Mycotoxins and the cereals industry-a review. International Journal of Food Science \& Technology, 17(1), 1-9. http://dx.doi.org/10.1111/j.1365-2621.1982.tb00153.x

PEREYRA, C.M. (2010). Fungi and Mycotoxins in Feed Intended for Sows at Different Reproductive Stages in Argentina. Veterinary Medicine International, 2010. http://dx.doi.org/10.4061/2010/569108

PHILliPS, S. I., WAREING, P. W., DUTTA, A., PANIGRAHI, S., \& MEDLOCK, V. (1996). The mycoflora and incidence of aflatoxin, zearalenone and sterigmatocystin in dairy feed and forage samples from Eastern India and $\begin{array}{lll}\text { Bangladesh. } & \text { Mycopathologia, } & 133(1),\end{array}$ http://dx.doi.org/10.1007/BF00437094

PITT, J.I. (1996). What are mycotoxins?; Australian Mycotoxin Newsletter, 7(4):1.

RAPER K, FENNELL D. (1965). The Genus Aspergillus. Baltimore, Williams and Wilkins.

RICHARD, E., HEUTTE, N., SAGE, L., POTTIER, D., BOUCHART, V. LEBAILLY, P., \& GARON, D. (2007). Toxigenic fungi and mycotoxins in mature corn silage. Food and Chemical Toxicology, 45(12), 2420-2425. http://dx.doi.org/10.1016/j.fct.2007.06.018

ROSA, C. A. R., KELlER, K. M., KELLER, L. A. M., PEREYRA, M. G., PEREYRA, C. M., DALCERO, A. M., CAVAGLIERI, L.R. \& LOPES, C. W. G. (2009). Mycological survey and ochratoxin A natural contamination of swine feedstuffs in Rio de Janeiro State, Brazil. Toxicon, 53(2), 283-288, http://dx.doi.org/10.1016/j.toxicon.2008.11.015 